$11-1-2021$

\title{
Win-At-All-Costs? Exploring Bottom-line Mentality as a Buffer between Athletic Director Servant Leadership and Coach Commitment
}

\author{
Matt Robinson \\ Schreiner University, mrobinson@schreiner.edu \\ Jun Woo Kim \\ Arcadia University, kimjw@arcadia.edu \\ Marshall Magnusen \\ Baylor University, Marshall_Magnusen@baylor.edu \\ Mitchell Neubert \\ Baylor University, Mitchell_Neubert@baylor.edu
}

Follow this and additional works at: https://trace.tennessee.edu/jasm

Part of the Business Commons, Education Commons, and the Social and Behavioral Sciences Commons

\section{Recommended Citation}

Robinson, Matt; Kim, Jun Woo; Magnusen, Marshall; and Neubert, Mitchell (2021) "Win-At-All-Costs? Exploring Bottom-line Mentality as a Buffer between Athletic Director Servant Leadership and Coach Commitment," Journal of Applied Sport Management: Vol. 13 : Iss. 1.

https://doi.org/10.7290/jasm136424

Available at: https://trace.tennessee.edu/jasm/vol13/iss1/2

This article is brought to you freely and openly by Volunteer, Open-access, Library-hosted Journals (VOL Journals), published in partnership with The University of Tennessee (UT) University Libraries. This article has been accepted for inclusion in Journal of Applied Sport Management by an authorized editor. For more information, please visit https://trace.tennessee.edu/jasm. 


\title{
Win-At-All-Costs? \\ Exploring Bottom-line Mentality as a Buffer Between Athletic Director Servant Leadership and Coach Commitment
}

\author{
G. Matthew Robinson \\ Jun Woo Kim \\ Mar Magnusen \\ Mitchell J. Neubert
}

\begin{abstract}
Servant leadership (SL), characterized by enduring qualities of genuine caring, humility, and empathy, has been positively associated with numerous leader effectiveness outcomes (e.g., employee satisfaction) across sport and non-sport settings. This study addresses the need to more thoroughly investigate follower characteristics that may allow servant leadership to be more (or less) effective in a sport context. Drawing from leader-member exchange (LMX) theory, this study predicted head coach bottom-line mentality (i.e. 1-dimensional, win-at-all-costs attitude) would negatively impact the relationship between athletic director SL and head coach commitment. Surveying a sample of 810 interscholastic high schools (HCs) across the USA, Structural Equation Modeling revealed SL's positive effect on head coach commitment. Analysis also revealed the interaction of SL and bottom-line mentality had a significant negative impact on commitment. Thus, when follower bottom-line mentality is win-at-all-costs, the positive influence of SL appears to be diminished.
\end{abstract}

Keywords: attitude, high school, interscholastic sport, leader, management, organizational behavior

G. Matthew Robinson is an Assistant Professor at Schreiner University

Jun Woo Kim is an Associate Professor at Arcadia University

Mar Magnusen is an Associate Professor at Baylor University

Mitchell J. Neubert is a Professor at Baylor University

Please send correspondence to G. Matthew Robinson, MRobinson@schreiner.edu 


\section{Introduction}

Servant leadership is a model based on ethics and other-centeredness (Greenleaf, 1977). Characterized by a calling to serve others, and enduring qualities of genuine caring, humility, and empathy (Robinson, Neubert, \& Miller, 2018), studies reveal consistent patterns of servant leader behavior yielding positive individual, team, and organizational outcomes in a variety of organizational settings (Van Dierendonck 2011). Within the realm of sport, servant leadership has been associated with outcomes such as leader effectiveness, follower job satisfaction, and organizational commitment (Robinson, Magnusen, Neubert, \& Miller, 2020).

Though servant leadership is growing in popularity, many questions remain about this leadership style (Neubert et al., 2016). One such question is: What factors contribute to the power of servant leader influence? More specifically, what follower characteristics may influence servant leadership to be more (less) effective? Herein, an attempt is made to answer each of these questions. In addressing these questions, follower bottom-line mentality was analyzed as a moderating variable in the relationship between athletic director (AD) servant leadership and head coach affective organizational commitment (i.e., the strength of one's emotional attachment and identification with an organization; Meyer \& Allen, 1997).

Bottom-line mentality represents "a 1-dimensional perspective that revolves around securing bottom-line outcomes to the neglect of competing priorities" (Greenbaum et al., 2012, p. 344), and it has been suggested as an area of investigation to extend servant leadership research (Robinson et al, 2020). Under normal circumstances, securing certain bottom-line outcomes is considered crucial to organizational success and often a prerequisite for employee rewards (Trevino, Brown, \& Hartman, 2003). However, when leaders too strongly focus on the bottom-line, it can become problematic if employees view it as the only objective for which to strive (Wolfe, 1988). Furthermore, the bottom-line mentality of followers can influence their response to leaders and the relationships formed between leaders and followers (Quade, McLarty, \& Bonner, 2020). In the realm of sports, a bottom-line-mentality with coaches can manifest as a win-at-all-cost attitude that emphasizes winning over the development and well-being of student-athletes and personal priorities above commitment to the organization. This approach not only influences relationships with student athletes but the relationships the coach has with superiors.

\section{Theoretical Foundation}

The relationships head coaches adopt with their ADs tend to influence the commitment of head coaches to the organization (Wayne, Coyle-Shapiro, Eisenberger, \& Liden, 2009). Leader-member exchange theory (LMX) is a relationship-based perspective of leadership focused on the two-way (dyadic) relationship between leaders and followers (subordinates) (Graen \& Uhl-Bien, 1995). With LMX, leaders are evaluated by followers and vice-versa. Congruence between the leader and follower on personal characteristics and priorities enhances the relationship and facilitates positive responses while a lack of congruence hinders the relationship and decreases positive responses (Zhang, Wang, \& Shi, 2012).

While servant leadership and the associated ethical and other-centered behaviors are generally viewed as a positive contribution to a relationship between a leader and follower, it is contrary to a bottom-line mentality. In other words, servant leadership is not likely to be perceived as congruent with the priorities of someone (e.g., coach or AD) with a bottom-line mentality. Thus, during the dyadic evaluation between the AD (leader) and head coach (subordinate), if priorities do not match, conflict may occur, and employee commitment may wane.

In most cases servant leadership is likely to have positive impact on follower commitment (Robinson et al., 2020). However, if there is incongruity between a leader's priorities and those of the follower, this positive result is less likely to happen. For instance, the existence of philosophical conflict between leaders (ADs) and subordinates (head coaches) may result in less committed followers. Accordingly, two research hypotheses are proposed:

$H^{1}$ : Servant leadership will have a positive impact on follower affective organizational commitment.

$H^{2}$ : Bottom-line mentality will negatively moderate the positive effects of servant leadership on follower affective organization commitment.

\section{Participants and Procedures}

\section{Methodology}

Online surveys were collected from a purposive sample of 810 interscholastic head coaches from 44 different states in the 
United States. Athletic directors were first contacted via e-mail and invited to participate. Questionnaires were then e-mailed to the head coaches who worked for participating ADs. The sample of respondents consisted of $72 \%$ male $(n=578)$ and $28 \%$ female $(\mathrm{n}=232)$, with an average age of 43 years. The mean organizational tenure for head coaches was 10.64 years $(\mathrm{SD}=$ 0.33), ranging from 1 to 48 years. Of the respondents, 84 percent were Caucasian, followed by Hispanic (6\%) and African American (5\%).

\section{Measure Development}

The survey questionnaire included three main research constructs corresponding to servant leadership, affective organizational commitment, and bottom-line mentality. All head coach instruments utilized a 7-point Likert scale where $1=$ "strongly agree" and 7 = "strongly disagree". Every item for each construct is included in Table 2. Head coaches evaluated servant leadership behaviors of their school's AD by completing the 14-item Servant Leadership Scale (Ehrhart, 2004). This general measure of servant leadership is based on seven categories: (1) forming relationships with subordinates, (2) empowering subordinates, (3) helping subordinates grow and succeed, (4) behaving ethically, (5) conceptual skill, (6) putting subordinates first, and (7) creating value for those outside the organization. Coaches also completed five-items evaluating their own affective organizational commitment (i.e., the strength of one's emotional attachment and identification with an organization; Meyer \& Allen, 1997). Finally, coaches rated their bottom-line mentality via a four-item measure (Greenbaum et al., 2012).

\section{Measurement Model}

\section{Data Analysis}

A confirmatory factor analysis (CFA) was conducted to validate underlying constructs in the measurement model using M-plus 6.1 (Muthén, \& Muthén, 2010). The measurement model was assessed with a minimal set of global fit indices recommended by McDonald and Ho (2002): (a) model chi-square, (b) the Steiger-Lind root mean square error of approximation (RMSEA; Steiger, 1990), (c) the Bentler comparative fit index (CFI; Bentler, 1990), and (d) the standardized root mean squared residual (SRMR).

\section{Structural Model}

To examine the hypothesized relationships between latent constructs (see Figure 1), latent moderated structural equations (LMS) using the XWITH command in M-plus were employed (Maslowsky, Jager, \& Hemken, 2015). The LMS method was adopted due to two major advantages: (a) statistical efficiency requiring estimation of only one parameter and (b) estimates of interactions that are unattenuated by measurement error (Busemeyer \& Jones, 1983; Maslowsky, et al., 2015). The structural models were evaluated in two steps (Muthén, 2012). The first step estimated the base structural model (Model 1) without the latent interaction term. The next step estimated the structural model with the latent interaction (Model 2).

In accordance with Maslowsky et al.s (2015) model assessment, the relative fit of Model 1 and Model 2 was compared using the log-likelihood ratio test. The log-likelihood ratio test can be used to determine whether the more parsimonious Model 1 represents a significant loss in fit relative to the more complex Model 2 (Satorra \& Bentler, 2010). If the log-likelihood ratio test is significant, Model 1 results in a significant loss of fit relative to Model 2. In short, the complex Model 2 fits the data better. The test for a log-likelihood ratio test is calculated using the following equation (Maslowkey et al., 2015):

$D=-2[(\log$-likelihood for Model 1)- (log-likelihood for Model 2)].

The value of $D$ is like the distribution of $\chi^{2}$, and the degrees of freedom to determine significance of $D$ is calculated by subtracting the number of parameters in Model 1 from the number of parameters in Model 2. Since the log-likelihood ratio test provides better model assessment for the LMS models than the robust difference test (Klein \& Moosbrugger, 2000), a log-likelihood ratio test was used to assess the LMS model. 


\section{Figure 1}

\section{Structural Model with a Latent Moderating Effect}

(a) Model 1 - Base Structural Model

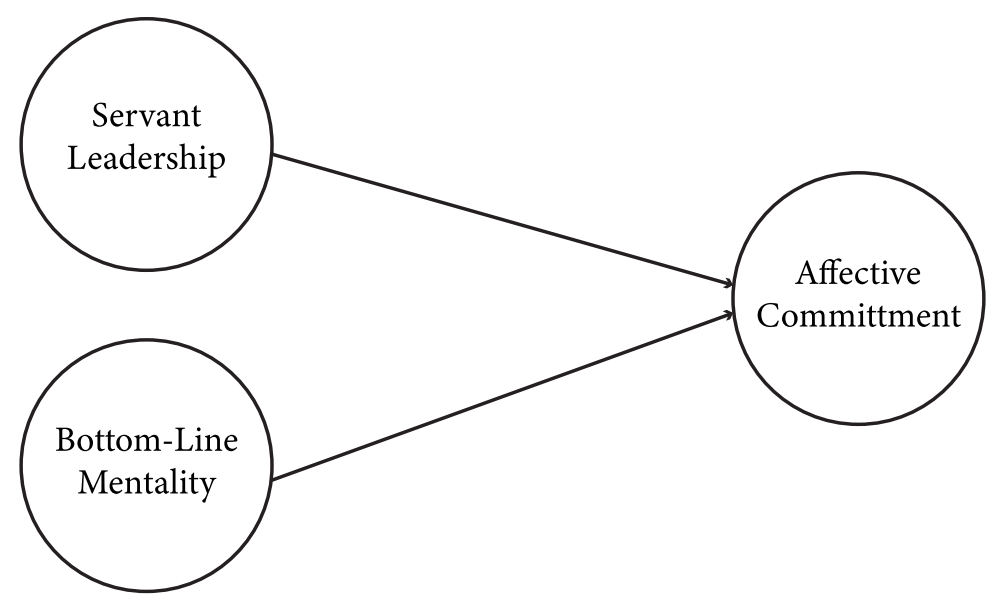

(b) Model 2 - Latent Moderated Structural Model

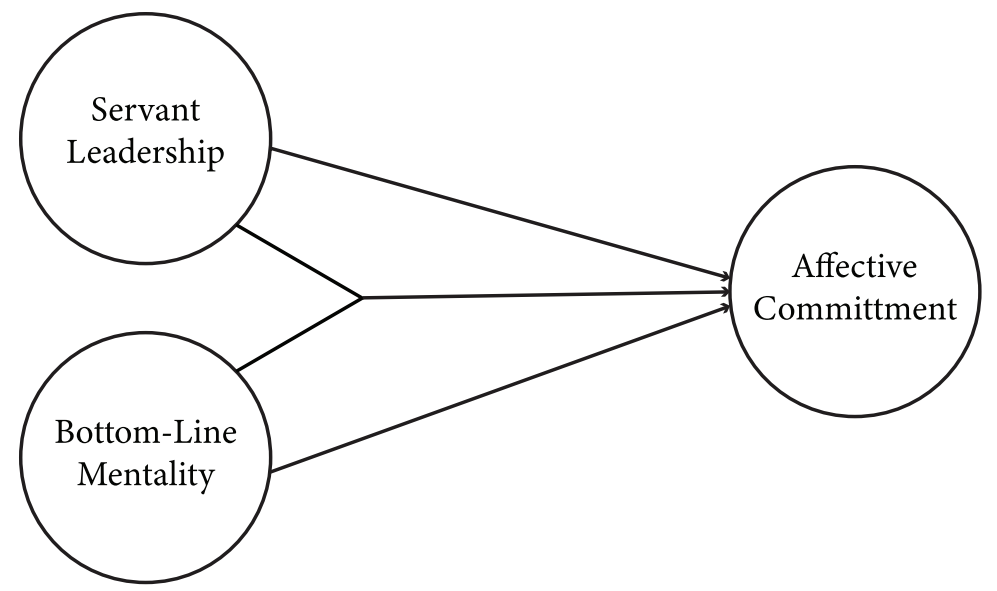

\section{Measurement Model}

\section{Results}

Table 1 provides the correlations among the latent variables, means, and standard deviations. Discriminant validity was established by comparing the AVE values for each construct with the squared correlations with any other constructs (Fornell \& Larcker, 1981). None of the squared correlations with any other constructs exceeded the AVE values for the four constructs. To adjust for multivariate nonnormality, Satorra-Bentler (S-B $\chi^{2}$ ) scaling method (Satorra \& Bentler, 2001) was used. Reported in Table 2 are the results of the measurement models.

The overall fit indices for the CFA show that the measurement model fits the data well [S-B $\chi^{2}(\mathrm{df})=799.40(206), p<$ $.001 ; \mathrm{CFI}=.94 ; \mathrm{TLI}=.93 ; \mathrm{RMSEA}=.06 ; \mathrm{SRMR}=.04]$, indicating that the measurement model adequately accounted for the covariance matrices of the data from the sample. Convergent validity was supported by all loadings being significant $(p<.01)$ and AVE values exceeding .50 (Fornell \& Larcker, 1981). The internal consistency of the measures was adequate because all of Cronbach's alpha coefficients were greater than the recommended cutoff point .70 (Nunnally, 1978). All scales demonstrated good reliabilities. 
Robinson et al.

\section{Table 1}

Descriptive Statistics and Correlation Matrix of Latent Constructs

\begin{tabular}{lcrc}
\hline Variables & 1 & 2 & 3 \\
\hline 1. Servant Leadership & 1.00 & & \\
2. Bottom-line mentality & 0.04 & 1.00 & \\
3. Affective commitment & 0.44 & -0.17 & 1.00 \\
Mean & 2.03 & 5.95 & 2.15 \\
S.D. & 1.03 & 0.96 & 1.06 \\
\hline
\end{tabular}

Note. $N=810, S D=$ standard deviation 


\section{Table 2}

Results of the CFA

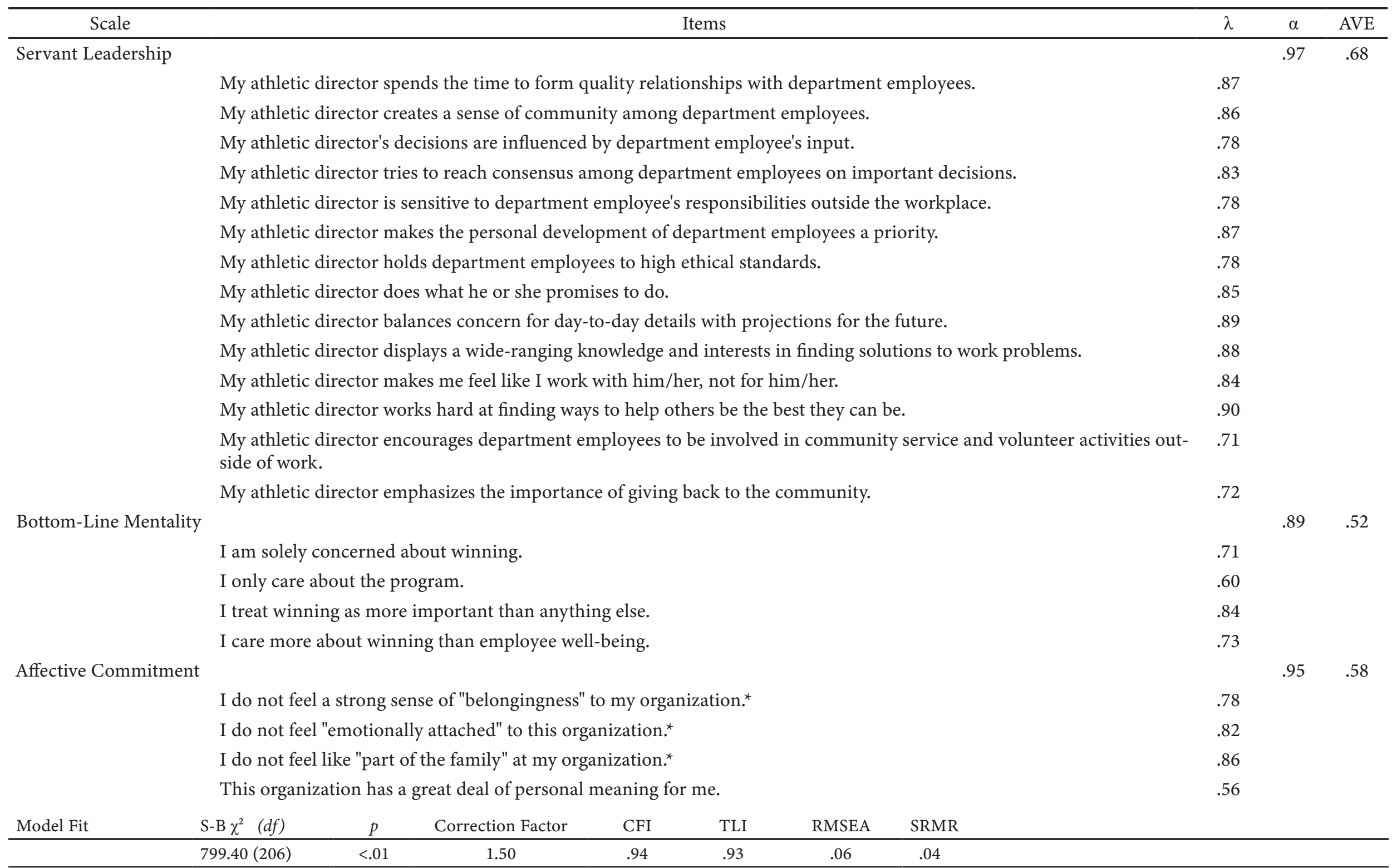

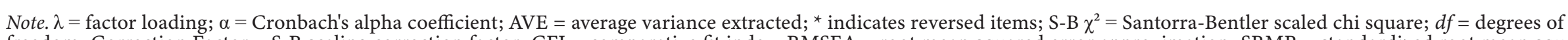

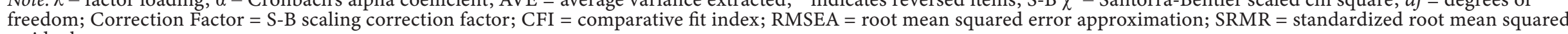




\section{Structural Model}

The resulting overall fit measures indicated that the proposed model was a good representation of the structures underlying the empirical data $\left[S-B \chi^{2}(d f)=795.79(206), p<.001 ; \mathrm{CFI}=.93 ; \mathrm{TLI}=.93\right.$; RMSEA $=.06$; SRMR $\left.=.04\right]$. As a result of the simultaneous equations, servant leadership had a significant positive effect on affective commitment $(\gamma=.45$, SE $=$ $.04, p<.01)$ and bottom-line mentality had a significant negative impact on affective commitment $(\gamma=-.19, \mathrm{SE}=.04, p<$ .01). Thus, $\mathrm{H}^{1}$ and $\mathrm{H}^{2}$ were supported.

The relative fit of Model 1 versus Model 2 determined via a log-likelihood ratio test $(D)$ comparing the log-likelihood values of Model 1 and Model 2, yielded a log-likelihood difference value of $D=-2[(-22018.053)-(-22010.451)]=15.204$. Based on the number of free parameters of Model 1 and Model 2, the difference in free parameters $=1$. Using a chi-square distribution, this log-likelihood ratio test proved significant $(p<.01)$, implying that Model 1 (without the interaction effect) represents a significant loss in fit relative to Model 2 (with the interaction effect). As $\mathrm{H}^{2}$ predicted, the interaction effect of servant leadership and bottom-line mentality had a significant negative impact on affective commitment $(\gamma=-.21, \mathrm{SE}=.07$, $p<.01)$. Thus, bottom-line mentality overrides the effect of servant leadership on affective commitment.

\section{Table 3}

\section{Structural Model Results with a Moderation Effect}

\section{Model 1}

Structural Path

$\gamma$ 1: Servant Leadership $\rightarrow$ Affective Commitment

\begin{tabular}{ccc} 
Path Coefficient & S.E. & $P$-Value \\
\hline $.45^{\star \star}$ & .04 & $<.01$ \\
$-.19^{\star \star}$ & .04 & $<.01$
\end{tabular}

$\gamma$ 2: Bottom Line Mentality $\rightarrow$ Affective Commitment

\begin{tabular}{ccccccccc} 
Model Fit & S-B $\chi^{2}(d f)$ & $p$ & Correction Factor & CFI & TLI & RMSEA & SRMR & Log-Likelihood \\
\hline & $795.79(206)$ & $<.01$ & 1.51 & .93 & .93 & .06 & .04 & -22018.053 \\
\hline
\end{tabular}

Model 2

Structural Path

$\gamma$ 1: Servant Leadership $\rightarrow$ Affective Commitment

$\gamma$ 2: Bottom Line Mentality $\rightarrow$ Affective Commitment

$\gamma$ 3: SL $\times$ BLM $\rightarrow$ Affective Commitment

\begin{tabular}{ccc} 
Path Coefficient & S.E. & $P$-Value \\
\hline $.54^{\star \star}$ & .06 & $<.01$ \\
$-.26^{\star \star}$ & .05 & $<.01$ \\
$-.21^{\star \star}$ & .07 & $<.01$
\end{tabular}

\begin{tabular}{ccccccccc} 
Model Fit & S-B $\chi^{2}(d f)$ & $p$ & Correction Factor & CFI & TLI & RMSEA & SRMR & Log-Likelihood \\
\hline- & - & - & - & - & - & - & -22010.451 \\
\hline
\end{tabular}

Note. $\mathrm{SL}=$ servant leadership, BLM= bottom line mentality.

\section{Figure 2.}

\section{Results of Latent Moderated Structural Model}

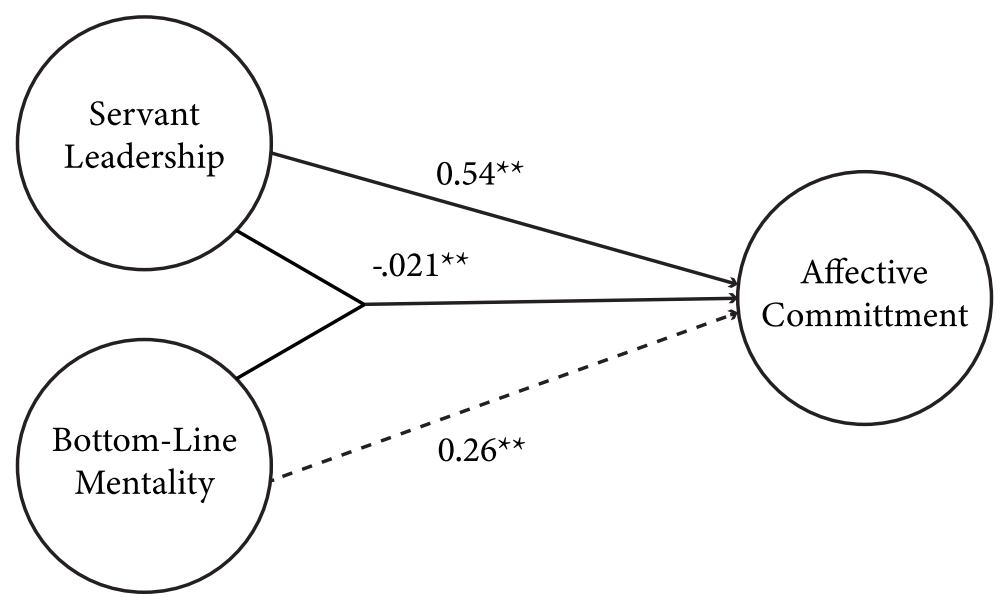




\section{Discussion and Application}

A novel contribution of this study is that it explores bottom-line mentality, a characteristic some coaches possess that appears to make servant leadership less effective. Though servant leadership of ADs independently had a positive effect on follower (coach) commitment, when head coaches placed winning above all other priorities (e.g., player well-being, ethical behavior), the influence of servant leadership was diminished. Practically, it appears ADs who aspire to be servant leaders should consider the bottom-line mentality of the head coaches they seek to hire. Disparate AD and coach philosophies can lead to conflict, turnover, decreased staff continuity, and a sport program that does not meet expectations. Individuals who are currently or who aspire to be an $\mathrm{AD}$ with a servant's heart need to understand how, if a bottom-line mentality is present with a coach, it may impact the extent to which this individual is committed to an organization with a servant leader.

To help ensure a good fit for employment, it is a good idea for ADs to portion a segment of time when interviewing prospective staff members to inquire about a coach's mentality and philosophy of leadership, as well as making it an area of focus when evaluating past coaching behaviors and checking with references. Creating a behavioral interview guide prior to interviewing candidates is a useful approach for $\mathrm{ADs}$ to consider. Behavioral interviewing is a technique wherein the interviewer focuses on a job candidate's past experiences by asking candidates to offer specific examples of how they previously demonstrated job-appropriate knowledge, skills, and abilities. An effective approach for implementing behavioral interview questions is the STAR method, which is often attributed to DDI, a global leadership consulting firm.

STAR is an acronym for Situation, Task, Action, and Result. To get a sense of whether a coach is compatible with a servant leadership style, the AD (interviewer) would ask the coach (job candidate) to explain the situation and tasks (actions) present in a behavioral example (e.g., "Tell me about an instance in which you had to follow instructions to complete a task that conflicted with your usual way of doing things."). Next, the interviewer asks the candidate to describe the actions taken to respond to the required tasks (e.g., "What did you do? How did you respond to the assignment?"). Lastly, the interviewer asks the candidate to explain the results of the actions (e.g., "How did the situation turn out out?"). The benefit of this approach for $\mathrm{ADs}$ is that, with practice, they can use this technique to predict future performance based on past behaviors and better identify coaches who are a good "fit" for their programs.

\section{Limitations and Future Directions}

Some limitations of this study need to be acknowledged. The design of the study and choice of measures may be possible sources of limitation. The bottom-line mentality (Greenbaum et al., 2012) and organizational commitment (Meyer \& Allen, 1997) measures are self-reported measures. This means the hypotheses tests could be vulnerable to common method variance. Though the CFA results appease some of this concern, future studies could improve upon this limitation by including outcome responses from both head coaches and ADs. Future studies in this area should also consider the longitudinal impact of servant leadership on follower bottom-line mentality and commitment by collecting data at multiple points over time during the $\mathrm{AD}$-head coach relational tenure. Additional areas for future research involve investigating how servant leadership ADs may influence the mentality of coaches with bottom-line mentality. Indeed, a question worth exploring is this: What interventions (actions) by servant leadership ADs diminish the bottom-line mentality of head coaches?

In closing, the present study found that AD servant leadership positively influenced head coach organizational commitment. It was also found that the bottom-line mentality present in head coaches detracted from their organizational commitment, even when led by servant leaders. Taken together, the current investigation affirms previous research on the relationship between servant leadership and follower commitment in a sport setting and highlights the salience of follower bottom-line mentality as a negative impact on this relational dynamic.

\section{References}

Bentler, P. M. (1990). Comparative fit indexes in structural models. Psychological Bulletin, 107, 238-246.

Busemeyer, J. R., \& Jones, L. E. (1983). Analysis of multiplicative combination rules when the causal variables are measured with error. Psychological Bulletin, 93, 549-562.

Cronbach, L. J. (1951). Coefficient alpha and the internal structure of a test. Psychometrika, 16, 297-334.

Ehrhart, M.G. (2004). Leadership and procedural justice climate as antecedents of unit-level organizational citizenship behavior. Personal Psychology, 57, 61-94. 
Fornell, C., \& Larcker, D. F. (1981). Evaluating structural equation models with unobservable variables and measurement error. Journal of Marketing Research, 18, 39-50.

Graen, G. B. \& Uhl-Bien, M. (1995). Relationship-based approach to leadership: Development of leader-member exchange (LMX) theory of leadership of 25 years: Applying a multi-level multi-domain perspective. Leadership Quarterly, 6, 219-247.

Greenbaum, R. L., Mawritz, M. B., Eissa, G. (2012). Bottomline mentality as an antecedent of social undermining and the moderating roles of core self-evaluations and conscientiousness. Journal of Applied Psychology, 97, 343-360.

Greenleaf, R. K. (1977). Servant leadership: A journey into the nature of legitimate power and greatness. New York: Paulist Press.

Klein, A, Moosbrugger, H. (2000). Maximum likelihood estimation of latent interaction effects with the LMS method. Psychometrika, 65, 457-474.

Maslowsky, J., Jager, J., \& Hemken, D. (2015). Estimating and interpreting latent variable interactions: A tutorial for applying the latent moderated structural equations method. International Journal of Behavioral Development, 39, 87-96.

McDonald, R. P., \& Ho, M. R. (2002). Principles and practice in reporting structural equation analyses. Psychological Methods, 7, 64-82.

Meyer, J.P., \& Allen, N.J. (1977). Commitment in the workplace: Theory, research and application. Thousand Oaks, CA: Sage.

Muthén, B. (2012, September 20). Latent variable interactions. Mplus. http://www.statmodel.com/download/LV\%20 Interaction.pdf.

Muthén, L. K., \& Muthén, O. M. (2010). Mplus (Version 6.0) [Computer software]. Los Angeles, CA: Muthén and Muthén.

Neubert, M. J. Hunter, E. M. and Tolentino, R. C. (2016). A servant leader and their stakeholders: When does organizational structure enhance a leader's influence? The Leadership Quarterly, 27, 896-910.

Quade, M. J., McLarty, B. D., \& Bonner, J. M. (2020). The influence of supervisor bottom-line mentality and employee bottom-line mentality on leader-member exchange and subsequent employee performance. Human Relations, 73, 1157-1181.

Robinson, G. M., Neubert, M. J., \&Miller, G. (2018). Servant leadership in sport: A review, synthesis, and applications for sport management classrooms. Sport Management Education Journal, 12, 39-56.

Robinson, G. M., Magnusen, M.J., Neubert, M., \& Miller, G. (2020). Servant leadership, leader effectiveness, and the role of political skill: A study of interscholastic sport administrators and coaches, International Journal of Sport Science \& Coaching, 16, 291-303.

Satorra, A., \& Bentler, P. M. (2001). A scaled difference chi-square statistics for moment structure analysis. Psychometrika, 66, 507-514.

Satorra, A.,\& Bentler, P. M. (2010). Ensuring positiveness of the scaled difference chi-square test statistic. Psychometrika, $75,243-248$.

Steiger, J. H. (1990). Structural model evaluation and modification: An interval estimation approach. Multivariate Behavioral Research, 25, 173-180.

Treviño, L. K., Brown, M., \& Hartman, L. P. (2003). A qualitative investigation of perceived executive ethical leadership: Perceptions from inside and outside the executive suite. Human Relations, 56, 5-37.

Van Dierendonck, D. (2011). Servant leadership: A review and synthesis. Journal of Management, 37, 1228-1261.

Wayne, S. J., Coyle-Shapiro, J. A.-M., Eisenberger, R., Liden, R. C., Rousseau, D. M., \& Shore, L. M. (2009). Social in fluences. In H. J. Klein, T. E. Becker, \& J. P. Meyer (Eds.), Commitment in organizations: Accumulated wisdom and new directions (pp. 253-284). NY: Taylor \& Francis.

Wolfe, D. M. (1988). Is there integrity in the bottom line: Managing obstacles to executive integrity. In S. Srivastva (Ed.), Executive integrity: The search for high human values in organizational life, (pp.140-171). San Francisco, CA: Jossey-Bass.

Zhang, Z., Wang, M. O., \& Shi, J. (2012). Leader-follower congruence in proactive personality and work outcomes: The mediating role of leader-member exchange. Academy of Management Journal, 55, 111-130. 